\title{
El esquivo perdón
}

\author{
Manuel Alejandro Prada Londoño ${ }^{1}{ }^{(\mathbb{D}}$, Alexander Ruiz Silva \\ Universidad Pedagógica Nacional, Colombia
}

Autor de correspondencia: ${ }^{1}$ maprada@pedagogica.edu.co Recibido: 10 de abril de 2021 Revisado: 30 mayo de 2021 Aprobado: 30 de agosto de 2021 Publicado: 11 de noviembre de 2021

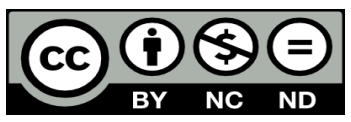

\section{Resumen}

En el artículo se hace una exploración preliminar del sentido y del valor otorgado al perdón por parte de reconocidos pensadores contemporáneos como Vladimir Jankélévitch, Jacques Derrida y Paul Ricœur. Se analizan estudios empíricos sobre el perdón realizados en Iberoamérica y Colombia, en contextos situados desde la psicología social, las ciencias políticas, la antropología y la educación. Luego, se concluye que el perdón trasciende la esfera íntima tanto del infractor como del agredido y está relacionado con el daño moral o el menoscabo de la dignidad de quienes sufren dicho daño, lo que es particularmente notorio en situaciones marcadas por la impunidad en contextos de violencia política. Además, se resalta la escasez de estudios sobre el perdón en el campo de la educación y la relevancia que tiene preguntarse si es posible enseñar a perdonar o si el perdón ha de tener lugar en la escuela únicamente como un horizonte de comprensión de la formación moral y política.

Palabras clave: perdón, justicia, reconciliación, educación, paz 


\title{
The elusive forgiveness
}

\begin{abstract}
This article is a preliminary exploration of the meaning and the value given to forgiveness by renowned contemporary thinkers such as Vladimir Jankélévitch, Jacques Derrida, and Paul Ricœur. An analysis is made on empirical studies on forgiveness carried out in IberoAmerica and Colombia, in contexts of social psychology, political science, anthropology, and education. Afterwards, it is concluded that forgiveness transcends the intimate sphere of both the offender and the aggrieved and is related to moral damage or undermining the dignity of those who suffer such damage, which is particularly notorious in situations characterized by impunity in contexts of political violence. Furthermore, the article highlights both the scarcity of studies on forgiveness in the field of education and the relevance of questioning whether it is possible to teach forgiveness or whether forgiveness should take place at school only as a horizon of understanding moral and political formation.
\end{abstract}

Keywords: forgiveness, justice, reconciliation, education, peace

\section{O elusivo perdão}

\section{Resumo}

Este artigo é uma exploração preliminar do significado e do valor dado ao perdão por renomados pensadores contemporâneos como Vladimir Jankélévitch, Jacques Derrida e Paul Ricœur. Analisa-se os estudos empíricos sobre o perdão realizados na Ibero-América e na Colômbia, em contextos de psicologia social, ciência política, antropologia e educação. Em seguida, conclui-se que o perdão transcende a esfera íntima tanto do ofensor quanto do prejudicado e está relacionado a danos morais ou que atentam contra a dignidade daqueles que sofrem tais danos, o que é particularmente notório em situações marcadas pela impunidade em contextos de violência política. Além disso, o artigo destaca tanto a escassez de estudos sobre o perdão no campo da educação quanto a relevância de se perguntar se é possível ensinar o perdão ou se o perdão deve acontecer na escola apenas como um horizonte de compreensão da formação moral e política.

Palavras-chave: perdão, justiça, reconciliação, educação, paz 
${ }^{1}$ La pregunta por el perdón ha ganado protagonismo en la sociedad contemporánea, por lo menos desde mediados del siglo XX, a propósito de los crímenes cometidos en el marco de la Segunda Guerra Mundial; luego, a partir de las violaciones sistemáticas de los derechos humanos en distintos países que padecieron cruentas guerras con otras naciones, dictaduras militares y conflictos armados internos; pero, especialmente, a propósito de los procesos de paz emprendidos para superar el horror. La cuestión del perdón, sus concepciones, usos y prácticas parecen estar claramente instalados en las ciencias sociales y las humanidades (Beltrán-Morillas et al., 2015; Griswold, 2007; Holmgren, 2012; Lefranc, 2018; Nussbaum, 2016; Villa-Castaño, 2020), al punto de que podemos hablar de estudios del perdón (Zembylas, 2012). No obstante, su desarrollo en el campo de la educación es apenas embrionario (Man Fat Wu, 2021; Ruiz, 2021; Ruiz \& Prada, 2020).

En Colombia, la discusión respecto a la pertinencia, las posibilidades y los límites del perdón, no solo desde el punto de vista conceptual, sino también como práctica ética y política, ha tenido un lugar relevante en la reciente investigación filosófica, sociológica y psicológica, en relación con iniciativas y procesos de paz y reconciliación (Chaparro, 2002, 2005), y en el marco del Acuerdo de Paz de fines de 2016, entre el Estado colombiano y la guerrilla de las FARC-EP.

A raíz de este complejo e inacabado proceso, se han dado algunas discusiones interesantes. Duica (2017a, 2017b) y Uribe (2017), por ejemplo, se preguntaron si el perdón es algo que puede exigirse o si espontáneamente se concede; si está circunscrito a una "provincia racional" - por ejemplo, la del cristianismo-; y si el perdón es algo que debe resolverse en la esfera estrictamente personal o enlaza implicaciones colectivas. En este debate, el perdón no configura un horizonte de comprensión plausible para restaurar los vínculos sociales, procurar la reconciliación, ayudar a restituir la dignidad o sanar heridas que, acaso, propicien lo que Arendt (2016) llama un nuevo comienzo.

Este "dictamen" se fundamenta en posturas contrarias al perdón si ello significa oscurecimiento de la verdad, impunidad, deslegitimación de las luchas por la justicia o negación del relato de quienes históricamente han sido silenciados. Asimismo, las críticas al perdón como horizonte ético y político están relacionadas con la imposibilidad de responder afirmativamente a la pregunta: ¿cómo es posible que yo pueda perdonar a quien me ha hecho tanto daño? (López, 2017, p. 104). Tal objeción es constitutiva de este campo de estudios y es asumida aquí como incentivo para el trabajo de clarificación conceptual que nos hemos propuesto realizar.

A la par de estas críticas a la plausibilidad del perdón como horizonte teórico-práctico para alcanzar la paz, circulan posturas que lo consideran una necesidad de las víctimas, los sobrevivientes y sus familias, razón por la cual se emprenden iniciativas que conducen -cuando no inducen- a perdonar (Narváez, 2017). Además, hemos oído declaraciones de perdón solicitado y concedido (López, 2017, Montaño, 2013), así como otras que, lejos de plantear una disyunción entre justicia y perdón, consideran que ambos pueden ir de la mano si se acude a la figura del perdón constructivo (Duque, 2017; Philpott, 2012), es decir, si se involucra el arrepentimiento y la reparación por parte del agresor; si se administra justicia,

1 Este artículo consigna desarrollos del proyecto de investigación: Comprensiones, sentidos y valoraciones del perdón en madres y hermanas de jóvenes víctimas de ejecuciones extrajudiciales: El caso de MAFAPO (Madres de Falsos Positivos) de la Universidad Pedagógica Nacional —CIUP, 2021. Código: DED-544-21—. 
por parte del orden institucional; y si se da alguna forma de sanación y reconstrucción de los vínculos sociales en los agredidos.

En lo que atañe al campo de la educación, en la escasa bibliografía encontrada se enfatiza que, si bien el perdón puede aprenderse, construirse o proyectarse, no hay precisamente consenso en relación con que pueda ser enseñado, al menos no como se enseñan contenidos o procedimientos disciplinares.

Uno de los aportes posibles a este asunto en un contexto tan complejo como el del posacuerdo en Colombia es ayudar a esclarecer los hilos que tejen el reto de la paz, del perdón y de la reconciliación, en y desde ámbitos formativos, especialmente cuando estos suscitan posiciones controvertidas. No es exagerado afirmar que, en las aulas de clase, en los medios de comunicación masiva y en una buena parte de las opiniones que se escuchan en la vida cotidiana, el problema de la paz en Colombia se plantea de forma binaria, como si esta tuviera que entenderse y traducirse en acciones personales, colectivas e institucionales concretas, únicamente mediante la asunción exclusiva de uno de los polos en disputa que considera su opuesto no solo errado, sino, además, excluyente. Así, en los debates pareciera que uno debe inclinarse por elegir justicia o perdón; justicia o paz; instituciones fuertes o negociación pacífica.

De hecho, es posible que muchos votantes del NO, en el plebiscito por la paz del 2016, más allá de los intentos de manipulación mediática y partidista, votaran de ese modo convencidos de que la opción por el SÍ significaba renunciar a cualquier posibilidad de justicia. Es comprensible que una sociedad que ha padecido interminables expresiones de violencia e impunidad no quiera renunciar a la justicia, aunque esté en juego la posibilidad de una paz negociada. Por supuesto, la justicia no era lo que se estaba plebiscitando. Sin embargo, la mencionada lógica excluyente se posicionó por esos días en la opinión pública. Como es sabido, tal lógica binaria, de tan fácil comprensión y adopción, está llena de falacias que es necesario desvelar.

\section{Aproximaciones teóricas al perdón}

Uno de los primeros filósofos del sigloXX en tematizar el perdón fue Vladimir Jankélévitch. Motivado por los acontecimientos de la Segunda Guerra Mundial, especialmente por las discusiones suscitadas a raíz de los juicios de Núremberg, este filósofo francés publicó en 1967 un libro titulado El perdón. Allí señala que "El perdón verdadero o falso... levanta el estado de excepción, liquida lo que el rencor sustentaba, resuelve la obsesión vindicativa. El nudo del rencor se desanuda" (2019, pp. 13-14). El perdón se presenta allí como un deber, una especie de "imperativo" que, sin embargo, tiene un carácter excepcional, difícil, insistente, al tiempo que representa un caso límite, un "movimiento del alma que no existe en la psicología corriente" (p. 8). Este movimiento, paradójicamente, es del orden de la gracia, del acontecimiento, reconocible en el límite de las posibilidades humanas. Su vocación no es la de permanecer como un estado, ni la de sobrevivir lo suficiente como para ser testigo de su propio heroísmo: "el impulso del perdón es tan impalpable, tan controvertible, que ahuyenta cualquier análisis” (p. 12). De ahí que la única filosofía posible al respecto es la apofática o negativa, pues no se puede asir el perdón puro, sino uno relativo, que está "contaminado" por el rencor, el cálculo, el interés y la previsión. 
Jankélévitch (2019) expone tres rasgos centrales del perdón. En primer lugar, se trata de un acontecimiento fechado, que adviene en la historia, precedido de una ofensa causada y sufrida, no solo en sentido "objetivo" o testificada como tal por otros, sino en sentido "subjetivo" - "me han ofendido, he sido dañado", de ahí que todo aquel que desdeñe el mal y minimice la injuria no puede perdonar, pero tampoco hacer inútil el perdón, porque no ha habido ofensa propiamente dicha-. Más adelante agrega:

El perdón apunta a una cosa que el malvado ha hecho, un acto que el malvado ha cometido, un daño que el malvado ha suscitado; el perdón no perdona solamente al ser, perdona al hacer, o más bien al haber hecho; perdona al ser de ese crimen. (p. 211)

En segundo lugar, el perdón es un don gracioso, un "obsequio gratuito del ofendido al ofensor". Como don, requiere que haya habido ofensa, lo que supone a su vez una ruptura de la relación entre ofendido y ofensor y un cierto esfuerzo por parte de quien perdona. De ahí que el perdón no pueda confundirse con la clemencia, que "no solamente es condescendiente, más bien es 'intransitiva'; es literalmente solitaria en su magnanimidad. La clemencia es un perdón sin interlocutor" (Jankélévitch, 2019, p. 15). Tampoco puede confundirse con la generosidad, que es "demasiado rica en recursos, y los recursos desbordan por sí mismos" (p. 16).

Esta característica es una ocasión para reflexionar sobre los vínculos y tensiones entre el perdón y la justicia. Como don, el perdón "pertenece, en efecto, al ámbito extralegal, extrajurídico de nuestra existencia; como la equidad, y mucho más aún, es una abertura en la moral vallada, una especie de aureola en torno a la ley estricta" (Jankélévitch, 2019, p. 21). Situar al perdón en este ámbito extralegal tiene como pretensión no perder de vista justamente que el mal se ha cometido, que el crimen ha tenido lugar y que ha de buscarse un modo de resarcirlo, lo que supone conocer los hechos, atribuir responsabilidades y establecer formas de reparación. Además, prosigue Jankélévitch (2019):

El perdón encuentra empleo cuando el agravio permanece inexpiado y la culpa irreparada, y mientras la víctima no ha sido indemnizada en su daño... Perdonar es dispensar al culpable de su pena, o de una parte de su pena, o liberarlo antes del cumplimiento de su pena; y por nada y a cambio de nada; gratuitamente, por añadidura. (p. 21)

De nuevo, aparece una paradoja que sigue jalonando la reflexión: ha habido crimen, no se puede resarcir, pero se sigue con la búsqueda de justicia; hay búsqueda de justicia, pero el perdón dispensa gratuitamente; hay gratuidad, pero esta no se confunde con impunidad.

El tercer rasgo del perdón es que en él hay una relación personal, transitiva: así como alguien ha ofendido a alguien, le ha hecho mal y, con ello, ha roto una relación personal y los lazos de la comunidad, en el perdón también alguien da algo a alguien y alguien pide o espera algo de alguien. El perdón restaura las relaciones entre personas concretas, de ahí que no puede confundirse con la clemencia, pues esta tiene más bien un carácter solitario; ni con la generosidad, porque esta tiende a realizarse con todos y con nadie en particular: "ignora la alteridad del otro, con mayor motivo ignora la relación con el otro" (Jankélévitch, 2019, p. 16).

En la exposición de Jankélévitch (2019) sobresale también su intento por distinguir el verdadero del falso perdón, o sus sustitutos. El primer sustituto es el que se da por desgaste 
temporal. Esto es, el mal cometido prescribe o se desgastan tanto sus efectos que se termina por olvidar la ofensa. Es como si el paso del tiempo fuera deshaciendo el acontecimiento. Contrario a esto, la experiencia de perdón requiere tener presente que "el tiempo puede paliar o borrar la culpa cometida, pero no puede nihilizar su comisión; neutraliza los efectos de la culpa, pero no puede aniquilar el hecho de la culpa" (p. 78). Ligada a este sustituto, hallamos la liquidación, que introduce la idea de que la culpa se paga, de que todo queda exculpado de algún modo, como si el mal sufrido por el malhechor hiciera prescribir el crimen y funcionara como incentivo para restituir las relaciones rotas. En realidad, en la liquidación no solo se pretende la desaparición del mal — podría decirse también que la promesa de no-repetición pierde su mordiente-; y se siguen anulando las relaciones, ya antes quebrantadas.

Otro sustituto del perdón es la excusa intelectiva. Se trata de la racionalización del mal, de un intento por comprender lo que lo excusaría. Sin embargo, no habría propiamente perdón, en la medida en que no habría un mal voluntario, o porque, al fin de cuentas, "no fue tan malo" aquello que pasó, por lo cual no hay nada que perdonar. Así, la excusa no es un acontecimiento, dado que se requiere tiempo para comprender. No es un don, pues hay razones para comprender. No supone una relación, porque no se dirige a nadie, carece de segunda persona (Barillas, 2019, p. 17) ${ }^{2}$.

Otro filósofo que se ha destacado por su reflexión sobre el perdón es Jacques Derrida, quien toma como punto de partida los traumas de la historia reciente, a partir de los cuales se han multiplicado los gestos y discursos de solicitud y concesión de perdón entre individuos y comunidades. Según expone en On Forgiveness (2001), el perdón pertenece a una herencia religiosa específica, la abrahámica, y se expresa en un lenguaje — gestos, símbolos, rituales y palabras - que recoge dicha herencia, aun si quienes lo piden o conceden no profesan algunas de las religiones allí contenidas, como es el caso de los gestos de solicitud de perdón por parte de líderes japoneses en el enfrentamiento bélico con Estados Unidos en la Segunda Guerra Mundial.

Para este filósofo, reconocer la herencia que recorre la dinámica del perdón invita a hacer un movimiento deconstructivo que permite asumir aquel como sustituto de la expiación, sucedáneo del castigo. Así, toma distancia de la idea de cálculo entre el mal cometido y la condonación de la pena. Contrario a esta lógica económica de intercambio entre crimen y castigo y de la idea de que se perdona con la condición de que haya una medida del mal cometido y el compromiso del perpetrador del crimen de cambiar su vida, o un gesto que garantice que habrá algún tipo de pago, Derrida propone que el perdón debe darse:

Allí donde no es ni pedido, ni merecido, incluso con respecto a lo peor del mal radical. El perdón no encuentra su sentido (si es que debe, al menos, preservar algún sentido, lo que no está asegurado), solo encuentra su posibilidad de perdón allí donde es llamado a hacer lo im-posible y a perdonar lo im-perdonable. (Derrida, 2015, p. 28)

Tal carácter incondicional del perdón enlaza algunas consideraciones. En primer lugar, se trata de una experiencia temporal que atañe al pasado, a un pasado que no termina de pasar, a la huella imposible de borrar dejada por el crimen y que se escapa a cualquier

2 Jankélévitch (2019) lleva mucho más allá el argumento para decir: “a fuerza de comprender todo, acabaremos descubriendo que los verdugos son las verdaderas víctimas de sus víctimas, y que las culpas estaban ¡repartidas!” (p. 136). 
representación (Derrida, 2015). No hay excusa del mal: este no se borra con el perdón, ni se expía. Esta suerte de referencia al daño se radicaliza en la idea de lo imperdonable, esto es, que el crimen perpetrado fue de tal magnitud, que el mal sufrido de tal naturaleza, que aun pudiendo resolverse - su castigo o su amnistía - en el terreno del derecho penal, no es susceptible de perdón. No obstante $-\mathrm{y}$ he aquí la paradoja—, solo lo que no puede pensarse como perdonable es precisamente lo que merece ser perdonado.

En segundo lugar, la experiencia temporal del perdón es relacional: la vive alguien respecto a otro - más allá de la disimetría de los intercambios o de alguna forma de superioridad-. Quien perdona no lo hace desde la altura de una soberbia calculadora o desde la prepotencia de la generosidad, sino que se disloca en su identidad, en su búsqueda de simetría consigo y con los otros. A su vez, quien es perdonado "no se confunde totalmente con la falta y el momento de la falta pasada, ni tampoco con el pasado general" (Derrida, 2015, p. 18). Esta relación permanece indecidible. Es "heterogénea respecto a toda determinación en el orden del saber, del juicio teóricamente determinante, de la presentación de sí de un sentido susceptible de apropiación" (p. 43). Esta postura implica, entonces,

una tensión o incluso una contradicción entre la ética hiperbólica de un perdón de lo imperdonable, incondicional, y esta economía corriente del perdón que domina la semántica religiosa, jurídica, e incluso política y psicológica del perdón, de un perdón contenido en los límites humanos antropo-teológicos del arrepentimiento, de la confesión, de la expiación, de la reconciliación o de la redención. (p. 27)

El tercer filósofo que nos ha servido de marco inicial de comprensión del perdón es Paul Ricœur, para quien esta experiencia hace parte de un marco más amplio que podemos llamar: "el trabajo de la paz". En un escrito de juventud titulado El hombre no violento y su presencia en la historia (2015), resalta que la mansedumbre, la compasión, la misericordia, la sed de justicia, la capacidad de perdonar o el trabajo por la paz son puestos como horizontes de la acción humana, como invitaciones a actuar de forma tal que se mantenga vivo el tejido del nosotros. Puede decirse, entonces, que el trabajo por la paz es una respuesta a un llamado originario a vivir juntos, condición humana plural recibida como don de la existencia.

Ahora bien, es pertinente señalar que tal horizonte no esconde la propensión humana a la guerra, al odio fratricida o a la venganza. De hecho, lejos de considerar una condición humana perversa - acaso "caída" -, este pensador prefiere apostar mucho más a la idea de una bondad originaria (Ricœur, 2009, p. 198). No obstante, por más originaria que sea la bondad, por más constitutiva de nuestra existencia que sea la llamada a la plenitud de la vida con y para los otros, por más despliegue de las potencialidades humanas que esté en acción cuando procuramos organizarnos en instituciones justas, en las que se decanta nuestro deseo de vivir con otros, no podemos perder de vista que el mal, en sus múltiples manifestaciones, especialmente como violencia, es una realidad humana que ha hecho y sigue haciendo presencia en la historia, incluso con muchos más efectos que cientos de acciones generosas que tejen la vida cotidiana.

Teniendo presentes estas consideraciones, Ricœur (2003) asume que el fondo en el que ha de leerse la experiencia del perdón es el de la profunda disimetría entre uno mismo y los otros. De este modo, el perdón es posible en los límites del reconocimiento mutuo, no porque se oponga a dicho reconocimiento, sino porque intenta plantear una alternativa 
al modo de reciprocidad que lo alienta, según el cual solamente "doy para recibir", "te reconozco para que me reconozcas".

Otra dimensión aquí implicada es la del "recibir". Perdonar, como se ha dicho antes, tiene que ver con una iniciativa, con una manera de dar, pero también con recibir. ¿De qué modo? Se recibe con la gratitud que es el santo y seña del movimiento de mutualidad en el que se configuran las relaciones entre pares que, a pesar de todo, se asumen de este modo. Por otro lado, para Ricœur (2003), recibir el perdón es sentirse reconocido, aunque la falta, el error o el crimen cometido supere los límites de lo tolerable. Justamente, allí en lo imperdonable radica el carácter extraordinario de la gratitud: aun a pesar de mis acciones, sigo siendo reconocido como persona, alguien me restituye dicho carácter, me dice: "vales más que tus actos" (p. 643).

Esta postura se contrapone a la idea de que solo somos la suma de nuestros actos. Por supuesto, pensar que no todos los actos de un perpetrador son canallas es lo que lo convierte en sujeto-objeto de perdón, de rehabilitación y de reivindicación. No puede darse al margen del reconocimiento de su responsabilidad ante el daño producido, razón por la cual el asunto del perdón - en crímenes políticos- enlaza no solo la esfera subjetiva, sino también la social y la jurídica.

Un aspecto más que configura la reflexión ricœuriana sobre el perdón está relacionado con el gesto de devolver, que complementa los de dar y recibir explorados en las líneas precedentes. Devolver es pieza clave del perdón, puesto que una gratitud paralizada deja intacta la distancia entre el que da y el que recibe y se acomoda a la fácil situación de la dependencia indiferente. En otras palabras, un perdón que no genera un compromiso carece de sentido, pues es el compromiso el que hace, en principio, posible la reparación y la restitución.

Hecho este recorrido, enseguida se revisarán algunos trabajos de carácter empírico relacionados con el perdón en contextos situados. Como se verá, no todos los trabajos revisados se sirven de estos referentes filosóficos, sino que acuden a perspectivas sociológicas, antropológicas y de la psicología social.

\section{Abordajes empíricos del perdón}

Más de cincuenta años de conflicto armado interno en Colombia han dejado abiertas las heridas de sus víctimas directas: generaciones de ciudadanos hemos aprendido a vivir juntos en el temor al otro, el resentimiento, los duelos mal elaborados, la impunidad, la reconciliación a medias y un esquivo perdón (Castrillón-Guerrero et al., 2018). Quizás sea este último una de las mayores deudas psicosociales y políticas de individuos y comunidades históricamente mancillados y revictimizados. El estudio del esquivo perdón en contextos situados y con colectivos humanos agredidos adquiere una enorme relevancia, como intentaremos ilustrar a continuación, con la presentación de algunas investigaciones realizadas en América Latina y en Colombia.

Para Menghi et al. (2017), el perdón es un constructo basado en la superación de los efectos negativos de un agravio susceptible de medición, en sus esferas afectiva, cognitiva y comportamental. En esta dirección, llevaron a cabo un estudio en Entre Ríos, Argentina, de carácter cuantitativo, en el que aplicaron distintas escalas de evaluación y gradación 
del perdón a un grupo de 170 estudiantes de secundaria, de escuelas públicas y privadas. Concluyen que el perdón tiene notables implicaciones en el desarrollo emocional y social de las personas, de tal modo que, cuando este es posible, el resentimiento y la inclinación hacia la retaliación suelen transformarse en compasión y generosidad, lo cual les permite a las personas agraviadas tener una sensación de paz.

Este trabajo es heredero de investigaciones que han enfatizado la importancia de medir el perdón con herramientas evaluativas confiables antes del inicio de procesos terapéuticos. En esta vía, para Guzmán (2010), dado que el perdón es un proceso que se da en el tiempo, la mejor manera de medirlo y de considerar su impacto es mediante la realización de estudios longitudinales, es decir, a partir de una mirada detenida a su evolución en la vida de las personas. La investigadora destaca que en Chile los trabajos con mayor divulgación se han centrado en las repercusiones de la violencia política en la vida de individuos y colectivos sociales. Entre estos trabajos se destaca el de Manzi y González (2007), quienes analizaron la relación entre perdón y reconciliación, a propósito del retorno de Chile a la democracia en 1990, en un grupo de 225 estudiantes universitarios que mantenían sus demandas de verdad y justicia con las víctimas de la dictadura. Dichos estudiantes asociaron claramente procesos de identificación y de compromiso cognitivo y emocional de los perpetradores exrepresores - con sus delitos del pasado y la posibilidad de perdón y reconciliación. Tales resultados refuerzan la idea de que el perdón es un asunto profundamente relacional en el que, como mínimo, se requiere de la participación activa de la parte agresora y de la agredida, pero, sobre todo, la intención de los primeros por afrontar e intentar reparar el dolor producido.

Vargas et al. (2017), por su parte, analizaron la relación entre perdón y algunas manifestaciones personales de la violencia —intimidación, humillación, violencia sexual, entre otras-, en 205 mujeres y 145 hombres mexicanos, entre los 18 y los 60 años de edad, encuestados en lugares públicos tales como parques, hospitales, centros comerciales, entre otros. Los investigadores encontraron una baja tendencia de los ofendidos a perdonar. De hecho, el hallazgo principal de su trabajo es que el perdón puede hacer las veces de reforzador positivo del mantenimiento de la violencia si el agresor no asume un auténtico compromiso de reconversión, esto es, de transformación de sus acciones punitivas y exclusoras por comportamientos respetuosos y considerados. Así, la reiteración de la falta, del delito, no solo obtura el perdón, sino que también erosiona la confianza en las relaciones sociales, de tal modo que el ciclo de la violencia solo puede romperse a partir de un perdón condicional, basado en el compromiso del agresor de no producir más dolor, pero también a partir de la toma de distancia - alejamiento- entre víctima y victimario.

De otro lado, Villa (2016) exploró la importancia del perdón en procesos de construcción de paz, como alternativa a la producción y sostenimiento de la violencia política en el conflicto armado interno en Colombia. La perspectiva psicosocial de su trabajo le permite afirmar que, en términos políticos, prevalece una forma de impunidad traslapada principalmente en un discurso religioso que hace soportar el peso de la paz y la reconciliación en los afectados. Se trata de una estructura de pensamiento religioso culturalmente extendida en la sociedad colombiana y latinoamericana que presupone una tendencia natural al perdón, sin que necesariamente se surtan las interacciones sociales y las exigencias políticas y jurídicas para que esto tenga lugar. Tal estructura remite a una suerte de "cinismo colectivo que se 
constituye como correlato moral de la impunidad, que logra instalar en la memoria social un sofisticado mecanismo de ocultamiento sistemático de la verdad" (p. 143).

Una de las experiencias citadas por Villa (2016) aborda el trabajo de la Asociación de Mujeres del Oriente Antioqueño (AMOR), conformada por profesionales y víctimas de distintas formas de violencia, sobre todo de violencia de género - maltrato, asesinato, tortura, violencia sexual- en esta región. Ante la ruptura de lazos sociales entre mujeres victimizadas y orilladas a la desconfianza por los vejámenes padecidos por parte de distintos actores armados, el trabajo consistió en la recuperación personal y la restauración de un sentido de responsabilidad compartida.

Su experiencia les ha permitido a las integrantes de la organización emprender un proceso de sanación personal, recomponer el tejido emocional de las comunidades y construir una memoria viva e incluyente. Sin embargo, Villa (2016) advierte de innumerables riesgos de obligar a las víctimas o afectados a perdonar a los perpetradores, a nombre de la paz o de la reconciliación. Desde su perspectiva, la experiencia de la organización AMOR se corresponde con algunos de los postulados de Gandhi, para quien no puede haber perdón desde la sumisión y la derrota, desde la resignación o la parálisis, sino desde la restitución de la dignidad y de la relación verdad-justicia. Por lo tanto, la insistencia en esta dupla puede contribuir a la superación del odio y los deseos de venganza, de tal modo que los procesos psicosociales no contradigan la gestión de la memoria, sino que, por el contrario, la promuevan y contribuyan a su consolidación.

En una dirección similar, Garrido (2008) considera que el perdón es un proceso micropolítico que posibilita la reconciliación y la convivencia pacífica. Desde el campo de la ciencia política, esta relación vinculante implica al menos tres fases sociocognitivas:

1. la reinterpretación del pasado violento.

2. la humanización del otro y de sí mismo.

3. el reconocimiento del otro, en tanto cooperante potencial.

En la primera, se dota de significados nuevos el hecho traumático a fin de hacer soportable su recuerdo y dar opción al encuentro. En la segunda, se construye o se libera la capacidad de agencia para reconocer la falibilidad humana. En la tercera, el acento está puesto en la (re)humanización del agresor y en la habilitación de su condición de interactuante potencial o actual.

Desde la óptica de Garrido (2008), el perdón es “un mecanismo político de transformación de las relaciones víctima-victimario en el marco de procesos de reconciliación” (p. 125). Aunque esta relación es, por supuesto, central, nos llama la atención la ausencia de apelación a terceros tales como los familiares y amigos directamente afectados, los testigos y los actores institucionales, tan importantes en la construcción y sostenimiento del vínculo restaurador que hace posible la convivencia, cuando esta tiene lugar.

Vale la pena subrayar que la violencia sostenida en el tiempo, planeada y ejecutada con fines de dominación es claramente institucionalizada (Garrido, 2008), la cual, en caso de conflictos armados de larga duración, como el colombiano, está cubierta por un amplio manto de impunidad. En este contexto, los procesos de perdón ocurren de forma 
excepcional. Por lo tanto, grandes grupos poblacionales han vivido un perdón suspendido en el tiempo, aplazado o negado, lo que ha significado aprender a vivir con una herida en el alma, que no termina de cicatrizar. Por más que el dolor se haya hecho soportable en el tiempo, no siempre todos logran conceder un perdón sin otredad. Esto quizás explique la enorme carga de resentimiento que se expresa en distintos ámbitos sociales en forma de violencia intrafamiliar, humor agresivo, hostilidad gratuita o indiferencia.

Desde una perspectiva marcadamente distinta, Pineda-Marín (2017) analiza las condiciones en las que el perdón no solo es posible, sino, sobre todo, necesario. Desde su visión, el perdón tiene lugar en las relaciones interpersonales, en las que una parte procede de manera injusta con la otra y le causa decepción o profundo dolor. Sin embargo, cuando se trata de casos de violencia extrema padecidos en la propia humanidad, en la de seres queridos o en "el cuerpo" de una comunidad más amplia, el asunto desborda el plano subjetivo e intersubjetivo - relación directa- y se sitúa en la esfera pública, en la que el dolor de las víctimas exige valoración sobre lo acontecido por parte de terceros: testigos, analistas, jueces, entre otros.

La misma investigadora cita un estudio previo (López-López et al., 2012), de carácter cuantitativo, en el que se diseñó y se aplicó a un grupo amplio de personas una escala sobre disposición a perdonar. Esto permitió hallar interesantes tendencias, entre ellas, que cuanto más atroz es el crimen, menos se está dispuesto a perdonar; que es menos difícil perdonar a quien ejecuta una orden para cometer un crimen que a quien lo planea y lo ordena; y que hay mayor disposición a perdonar al agresor cuando este muestra señales claras de arrepentimiento y lleva a cabo acciones de reparación. Por más que estas previsiones parezcan obvias, indican que la desproporción del delito cometido y la intensidad del dolor padecido presuponen, en buena medida, una especie de continuum que va desde lo fácilmente perdonable a lo imperdonable. Por supuesto, el asunto es mucho más complejo que la obtención de un criterio de ordenación y clasificación del daño padecido o la disposición de las personas a absolver a sus agresores, justamente porque el mayor reto ético y político que se plantea es qué hacer frente a lo imperdonable.

Al respecto, Henao (2016) considera que el perdón no ha sido, precisamente, la principal herramienta para el resarcimiento de individuos o comunidades violentadas en el conflicto armado interno colombiano. Su estudio, enmarcado en la sociología cultural, consistió en contrastar los testimonios de víctimas de violencia política con los discursos que sobre los mismos hechos circulan en los medios de comunicación, lo cual permitió explicitar una enorme brecha entre ambas narrativas. Mientras los relatos de las víctimas se encuentran signados por anhelos de reparación incontestados, la mayoría de las veces los relatos de los medios están signados por pretensiones normativas respecto a una reconciliación que, más pronto que tarde, "debería" permitirnos convivir pacíficamente. Se plantea así la tensión entre un perdón esquivo y otro que "directa" y "necesariamente" desemboca en la reconciliación.

Vale la pena añadir que lo imperdonable no solamente se refiere a crímenes atroces, que obturan la reconciliación entre los directamente involucrados, sino, también, a un daño tan intenso en las víctimas que no logra activar procesos de perdón. Tales acontecimientos suelen caer en la impunidad, toda vez que transitan por el olvido inducido, la indiferencia 
o la negación institucional. Lo imperdonable no es, entonces, solamente lo que no se está dispuesto o cuesta demasiado perdonar, sino también aquello que cae fuera del registro del perdón; en otras palabras, lo que es negado como objeto del mismo: el daño rehuido, los crímenes no reconocidos, las vidas tratadas como prescindibles, el sufrimiento oculto.

Por su parte, Cortés et al. (2016) llevaron a cabo un estudio en Bogotá, con base en entrevistas semiestructuradas a 45 hombres y mujeres, en un amplio rango de edad -1865 años-, pertenecientes a distintos niveles socioeconómicos, mediante el cual exploraron sus ideas y creencias sobre la relación perdón-reconciliación. Entre las tendencias más significativas encontradas, se destacar la apelación de los entrevistados al encuentro y al diálogo como posibilidad de establecimiento de dicha dupla, así como la alusión a un compromiso de no repetición por parte del agresor y la asunción de consecuencias por sus agravios. De esa manera, al menos como ideal normativo, los entrevistados apelan a un principio moral y jurídico desde el cual la relación perdón-reconciliación no entra en disyunción con la justicia. Así, más que aludir a experiencias de la vida cotidiana en las que casi todas las formas de perdón son imperfectas, los entrevistados insisten en la necesidad de construir condiciones más equitativas, especialmente, para las víctimas de la violencia.

\section{Algunos estudios en el campo de la educación}

González y Fuentes (2012) enfatizan que, a pesar de la enorme importancia de la experiencia y del aprendizaje del perdón en procesos psicosociales y políticos, este asunto se encuentra por fuera de las modas y tendencias educativas, lo que explica la notoria escasez de trabajos de investigación o de innovación en este campo del saber y su casi nula concreción curricular. Por tal razón, se preguntan por procesos de perdón en contextos escolares. "Como toda experiencia humana, el perdón necesita ser educado y por ello, ni la familia ni la escuela pueden ignorarlo" (p. 485). Su perspectiva se funda en la idea de que aprender a perdonar significa reconocer que se ha infringido dolor, que tal dolor es inmerecido e injustificable y que, para seguir adelante, se requiere liberarse de los sentimientos negativos implicados. Tal aprendizaje es de enorme complejidad y enlaza, en algunas ocasiones, experiencias de solidaridad con otros que también han sido mancillados, así como con agresores conscientes, arrepentidos y en proceso de reparar el mal cometido. Además, afirman:

El perdón supone reconocer el daño y la pena que conlleva, enfrentarse al poder de destrucción que ese mal comporta. El educador debe ayudar a mirar ese mal cara a cara y a valorarlo justamente, sin relativizarlo ni agravarlo. Debe consolar sin fomentar la evitación de la mirada y las consecuencias que requiere el "caer en la cuenta" de ese mal. (p. 486)

En esa medida, en los procesos formativos no resulta conveniente ni recomendable evitarles a los estudiantes el conocimiento de situaciones agobiantes, ya que las personas también aprendemos de las experiencias negativas. Aprender a perdonar es aprender a enfrentar el dolor y el sufrimiento preservando la dignidad. Ahora bien, si la magnanimidad del perdón reside en la potenciación de la capacidad de dar, dicho don no puede otorgarse de manera forzada. Ha de ser voluntario y ligado al esfuerzo y la convicción restauradora del agresor.

Para investigadores como Garrido (2008), por su parte, el perdón es un mecanismo que 
se aprende, tanto a nivel individual como colectivo:

El paso del deseo de retaliación hacia el perdón implica un proceso de aprendizaje, esto es, de transformación de las reglas que constituyen los modelos mentales, en este caso relacionados con los códigos de equivalencia social. Aunque se suele dar espacio a la reflexión, este proceso de aprendizaje estaría influido, en gran medida, por los efectos de las emociones. (p. 140)

Respecto al "aprendizaje del perdón” se destacan estudios como el de Lin et al. (2011), para quienes el perdón puede contribuir a las discusiones actuales sobre la educación del carácter, que ha de incluir formación en hábitos, seguimiento de normas, capacidad de autonomía - reflexión y decisión-, así como asunción de valores individuales y comunitarios. Para los autores, el perdón sería uno de esos valores éticos que tendría que promoverse en currículos estructurados.

Este estudio sitúa dos dimensiones morales del perdón: virtud y razonamiento moral. La primera supone la capacidad de compasión, comprensión del otro, generosidad y amor; la segunda implica la capacidad de pensar — razonar - cómo responder a un trato injusto, de entender al agresor desde su propia perspectiva y de sopesar la injusticia. Estas dos dimensiones se ponen en juego en el Forgiveness Process Model que comprende cuatro fases:

1. comprensión de cómo alguien ha sido herido por las acciones de otro.

2. exploración de las vías de respuesta al daño sufrido.

3. trabajo de comprensión de las razones que llevaron al agresor a actuar de determinada manera, capacidad de empatía y desarrollo de la compasión.

4. el perdón propiamente dicho.

Estas fases, además, conforman los llamados Forgiveness Education Curricula, implementados en Irlanda del Norte y en Estados Unidos, que pretenden que los niños:

1. aprendan cinco conceptos relacionados con el perdón: valor inherente a todas las personas, amor, bondad, respeto y generosidad.

2. entiendan formas de trato injusto.

3. identifiquen posibles respuestas al mismo.

Por otra parte, la investigación de Zembylas y Michaelidou (2012), realizada con maestros de una comunidad griega en Chipre, explora cómo los maestros definen el perdón en una sociedad atravesada por traumas históricos y conflictos políticos; sus reservas respecto al perdón y las oportunidades pedagógicas para hacerlo posible. Basados en la noción de pedagogías del perdón, cuyo propósito es estudiar y diseñar intervenciones en escuelas y hacer un análisis crítico de sus límites y posibilidades, los investigadores analizaron los puntos de vista de 24 maestros de primaria y secundaria -17 hombres y 7 mujeres, entre 25 y 60 años- de la parte griega de Chipre. Estos maestros, en su mayoría, habían sido educados inicialmente bajo el lema "no olvido, lucho", que refleja el resentimiento contra lo que los chipriotas griegos consideran invasión turca, en 1974. Entre los resultados se destaca la predominancia de la no aceptación del perdón y la concepción de que este es un proceso puramente personal. 
De otro lado, los hallazgos del estudio enfatizan que un auténtico perdón es imposible, o no se merece, o es inapropiado o, si se da, no supone el restablecimiento de las relaciones entre agresores y agredidos. Respecto a las condiciones para el perdón, los maestros entrevistados coincidieron en que debe haber conciencia de que se obró mal, expresión de arrepentimiento y promesa de no repetición. Otros pusieron como condición la comprensión de las razones que el agresor tuvo para actuar de la forma en que lo hizo. A propósito de la esfera colectiva, estos maestros consideraron que el perdón es absurdo, inmoral, y reconocieron que una de las dificultades para asumirlo es que ellos mismos habían crecido considerando al otro - chipriota no griego- como su enemigo. Se destaca también que las mujeres entrevistadas son más cautelosas y escépticas que los hombres respecto al perdón, y que los más jóvenes son menos abiertos al mismo y presentan más condiciones para que este sea posible.

\section{Consideraciones finales}

La historia reciente de nuestro país cuenta con un número indefinido de víctimas sin reclamantes y de horrores velados, como si se tratara de un teatro de ilusiones en el que su figura central es un mago que, en lugar de sacar conejos de un sombrero, captura buena parte del dolor de la audiencia y lo oculta tras una cortina y, acto seguido, se retira del escenario como si nada hubiera sucedido. Aquí lo imperdonable adquiere la forma de amnesia inducida, de moratoria perenne. En términos sociales y políticos, el perdón trasciende la esfera íntima del infractor. No basta con que este se sienta absuelto por Dios - cualquiera sea su idea o representación - , la vida, la naturaleza o el destino. Se requiere la aquiescencia del agredido o de quien lo represente. Justamente, en este plano interpersonal se hace necesaria la participación de otros actores sociales que presencien, testifiquen, apoyen, soporten o garanticen la promesa que enlaza tanto el perdón solicitado como el concedido. En un sentido negativo, el valor de la promesa reside en la detención de la agresión y, en un sentido positivo, en la tolerancia de la presencia del otro en el ámbito social más amplio, lo que no necesariamente implica familiaridad, amistad o cercanía.

De otro lado, el perdón trasciende la esfera íntima del agredido, pues, por más que se esté dispuesto a perdonar para sanar y seguir adelante, sin la interacción con el agresor o quien lo represente, su indulgente actitud no enlaza promesa alguna, en tanto no habría un otro a quien proferírsela, ni compromiso de futuro cumplimiento. Quien perdona sin la decisión o participación del perpetrador circunscribe el perdón a su mundo psíquico, movido por la necesidad de paz interior. Muchas víctimas o sobrevivientes eligen voluntariamente esta condición, al no contar con otra alternativa. A estas formas de perdón las podríamos denominar perdón sin otredad, esto es, intrapersonal, al margen de la esfera pública, sin efectos en la restauración de una comunicación interpersonal segura y justa entre los implicados en los episodios del daño; en el primer caso, en ausencia de munificencia, y en el segundo, con su plena realización.

En lo que respecta a iniciativas educativas - investigativas y pedagógicas - se requiere tomar recaudos, a fin de no trivializar el perdón al confundirlo con la solicitud de disculpas por asuntos que, si bien importan, no merecen ser abordados a la luz de las exigencias del primero, cuya profundidad y complejidad ya se ha venido señalando a lo largo del presente escrito, especialmente porque el perdón está relacionado con el daño moral o el menoscabo de la dignidad de quienes sufren dicho daño, y esto es particularmente notorio 
en situaciones marcadas por la impunidad en contextos de violencia política. Finalmente, aunque haya un relativo consenso respecto de que el perdón se aprende, se propicia y se desarrolla, no existe ningún acuerdo sobre la idea de que se pueda enseñar a perdonar. Si fuese así, el asunto se resolvería en el diseño y aplicación de eficaces y persuasivas estrategias y dispositivos escolares o sociales. Está claro que en todo caso prevalece la voluntad, la capacidad de decisión y la prodigalidad del agredido, en observancia de la construcción o reconstrucción de condiciones de justicia.

\section{Referencias}

Arendt, H. (2016). La promesa de la política. Paidós; Booket.

Barillas, L. (2019). Presentation. En V. Jankélévitch. Le pardon (pp. I-XXIV). Flammarion.

Beltrán-Morillas, A., Valor-Segura, I., \& Expósito, F. (2015). El perdón ante transgresiones en las relaciones interpersonales. Psychosocial Intervention, 24(2), 71-78. https://dx.doi. org/10.1016/j.psi.2015.05.001

Castrillón-Guerrero, L., Riveros, V., Knudsen, M., López, W., Correa-Chica, A., \& Castañeda, J. (2018). Comprensiones de perdón, reconciliación y justicia en víctimas de desplazamiento forzado en Colombia. Revista de Estudios Sociales, 63, 84-98. https://doi. org/10.7440/res63.2018.07

Chaparro, A. (2002). Cultura, política y perdón. Universidad del Rosario.

Chaparro, A. (2005). La función crítica del perdón sin soberanía en procesos de justicia transicional. En A. Rettberg (Ed.), Entre el perdón y el paredón. Preguntas y dilemas de la justicia transicional (pp. 233-258). Ediciones Uniandes.

Cortés, A., Torres, A., López-López, W., Pérez, D., \& Pineda-Marín, C. (2016). Comprensiones sobre el perdón y la reconciliación en el contexto del conflicto armado colombiano. Psychosocial Intervention, 25(1), 19-25. http://dx.doi.org/10.1016/j.psi.2015.09.004

Derrida, J. (2001). On Cosmopolitanism and Forgiveness. Routledge.

Derrida, J. (2015). Perdonar. Lo imperdonable y lo imprescriptible. Avarigani.

Duica, W. (2017a). Redescribirnos. Una alternativa pragmatista a la imposibilidad del perdón. En T. Mosquera (Coord.), ¿Venganza o perdón? Un camino hacia la reconciliación (pp. 63-74). Planeta; Fundación para la Reconciliación.

Duica, W. (2017b). Respuesta a Ángela Uribe. Ideas y valores, 66(165), 441-446. http:// dx.doi.org/10.15446/ideasyvalores.v66n165.68481

Duque, J. (2017). De las amnistías y el perdón. En T. Mosquera (Coord.), ¿Venganza o perdón? Un camino hacia la reconciliación (pp. 127-145). Planeta; Fundación para la Reconciliación.

Garrido, E. (2008). El perdón en procesos de reconciliación: el mecanismo micropolítico del aprendizaje para la convivencia. Papel Político, 13(1), 123-167.

González, M., \& Fuentes, J. (2012). Los límites de las modas educativas y la condición humana. Un hueco para la educación de las grandes experiencias: el perdón. Revista Española de Pedagogía, 253, 479-493. https://revistadepedagogia.org/wp-content/ uploads/2012/09/253-05.pdf 
Griswold, C. (2007). Forgiveness. A Philosophical Exploration. Cambridge University Press.

Guzmán, M. (2010). El perdón en relaciones cercanas: conceptualización desde una perspectiva psicológica e implicancias para la práctica clínica. Psykhe, 19(1), 19-30.

Henao, L. (2016). Análisis sociológico del perdón: discursos hegemónicos y contra-hegemónicos [Tesis de Maestría, Universidad Nacional de Colombia]. Repositorio Institucional Biblioteca Digital UN. https://repositorio.unal.edu.co/handle/unal/56299

Holmgren, M. (2012). Forgiveness and Retribution. Responding to Wrongdoing. Cambridge University Press. https://doi.org/10.1017/CBO9781139086165

Jankélévitch, V. (2019). Le pardon. Flammarion.

Lefranc, S. (2018). Politiques du pardon. Presses Universitaires de France.

Lin, W., Enright, R., \& Klatt, J. (2011). Forgiveness as character education for children and adolescents. Journal of Moral Education, 40(2), 237-253. https://doi.org/10.1080/03057 240.2011 .568106

López, E. (2017). Más allá de la venganza: la generosidad el dar perdón y el valor de pedir perdón. En T. Mosquera (Coord.), ¿Venganza o perdón? Un camino hacia la reconciliación (pp. 95-110). Planeta; Fundación para la Reconciliación.

López-López, W., Pineda, C., Murcia, M., Perilla, D., \& Mullet, E. (2012). Colombian Lay People's Willingness to Forgive Different Actors of the Armed Conflict: Results from a Pilot Study. Psicológica, 33, 655-663.

Man Fat Wu, M. (2021). Forgiveness Education From an Hegelian Perspective. Journal of Peace Education, 18(1), 92-112. https://doi.org/10.1080/17400201.2021.1873757

Manzi, J., \& González, R. (2007). Forgiveness and reparation in Chile: The role of cognitive and emotional intergroup antecedents. Peace and Conflict: Journal of Peace Psychology, 13(1), 71-91. https://doi.org/10.1037/h0094025

Menghi, M., Rodríguez, L., Candela, M., \& Moreno, J. (2017). Adaptación de la escala de probabilidad de perdón a población adolescente argentina. Interdisciplinaria, 34(2), 489498.

Montaño, J. (2013, 31 de octubre). Monumento recuerda a mártires de masacre de «Las Brisas». El Tiempo. http://www.eltiempo.com/archivo/documento/CMS-13152941

Narváez, L. (2017). Entre economía política del odio y cultura ciudadana del perdón. En T. Mosquera (Coord.), ¿Venganza o perdón? Un camino hacia la reconciliación (pp. 29-59). Planeta; Fundación para la Reconciliación.

Nussbaum, M. (2016). Anger and Forgiveness: Resentment, Generosity, Justice. Oxford University.

Philpott, D. (2012). Just and Unjust Peace: An Ethic of Political Reconciliation. Oxford University.

Pineda-Marín, C. (2017). ¿Puede haber reconciliación sin perdón? Innovación y Ciencia, 14(1), 22-31. 
Ricour, P. (2003). La mémoire, l’histoire, l’oubli. Seuil.

Ricoeur, P. (2009). Philosophie de la volonté, vol. 2: Finitude et culpabilité. Points.

Ricœur, P. (2015). El hombre no violento y su presencia en la historia. En Historia y verdad (pp. 271-283). Fondo de Cultura Económica

Ruiz, A. (2021). Para que no me olvides. Memoria histórica y educación para la paz en el aula. Universidad Pedagógica Nacional.

Ruiz, A., \& Prada, M. (2020). Didáctica de la fantasía. La formación del niño como sujeto de derechos. Universidad Pedagógica Nacional; La Carreta.

Uribe, Á. (2017). Sobre "Redescribirnos. Una alternativa pragmatista a la imposibilidad del perdón” de William Duica. Ideas y valores, 66(164), 408-412. https://doi.org/10.15446/ ideasyvalores.v66n164.65008

Vargas, B., López, M., \& Cortés, E. (2017). ¿Qué significa el perdón en el ciclo de la violencia? Psicología Iberoamericana, 25(2), 70-83.

Villa, J. (2016). Perdón y reconciliación: una perspectiva psicosocial desde la noviolencia. Polis. Revista Latinoamericana, 15(43), 131-157. http://dx.doi.org/10.4067/S071865682016000100007

Villa-Castaño, L. (2020). El perdón estratégico: una necesidad para vivir juntos. Utopía y Praxis Latinoamericana, 25(89), 199-210. https://orcid.org/0000-0003-3510-3870

Zembylas, M. (2012). Suffering, Memory and Forgiveness: Derrida, Levinas and the Pedagogical Challenges Of Reconciliation in Cyprus. En P. Ahluwalia; S. Atkinson; P. Bishop; P, Christie; R, Hattam \& J. Matthews (Eds.), Reconciliation and pedagogy (pp. 45-64). Routledge

Zembylas, M., \& Michaelidou, A. (2012). Teachers' Understandings of Forgiveness in a Troubled Society: An Empirical Exploration and Implications for Forgiveness Pedagogies. Pedagogies: An International Journal, 6(3), 250-264. https://doi. org/10.1080/1554480X.2011.579081. 